\title{
The Biopsychosocial Model 40 Years On
}

\begin{abstract}
The first chapter outlines George Engel's proposal of a new biopsychosocial model for medicine and healthcare in papers 40 years ago and reviews its current status. The model is popular and much invoked in clinical and health education settings and has claim to be the overarching framework for contemporary healthcare. On the other hand, the model has been increasingly criticised for being vague, useless, and even incoherent-clinically, scientifically and philosophically. The combination of these two points signifies something of a crisis in the conceptual foundations of medicine and healthcare. We outline some of the emerging evidence implicating psychosocial as well as biological factors in health and disease, and propose the following solution to the vagueness problem: that the scientific and clinical content of the model relates to specific conditions and stages of conditions, so that there is, for example, a biopsychosocial model of cardiovascular disease, diabetes or depression. Much the same point applies to the narrower biomedical model. However this raises the question: what is the point of having a general model? Our response is that it is needed to theorise biopsychosocial interactions in health and disease. In the light of historical prejudices against psychosocial causation deriving from physicalist reductionism and dualism, recognised by Engel and current commentators on the biopsychosocial model, this is a non-trivial task that occupies subsequent chapters.
\end{abstract}

(C) The Author(s) 2019

D. Bolton and G. Gillett, The Biopsychosocial Model of Health and Disease, https://doi.org/10.1007/978-3-030-11899-0_1 
Keywords Biomedical model - Biopsychosocial model - Philosophy of medicine - Medical models

\subsection{Doing Well-But with Underlying Problems}

\section{Engel's Proposed Improvement on the Biomedical Model}

In his classic paper published in 1977 George Engel proposed a new model for medicine, the biopsychosocial model, contrasted with the existing biomedical model [1]. While recognising the great advances in biomedicine, Engel argued that nevertheless the biomedical model was limited, and insufficient for many aspects of medical science and healthcare. These limitations were extensive, comprising failure to take account of the following: the person who has the illness, the person's experience of, account of and attitude towards the illness; whether the person or others in fact regard the condition as an illness; care of the patient as a person; for some conditions such as schizophrenia and diabetes, the effect of conditions of living on onset, presentation and course; and finally, the healthcare system itself also cannot be conceptualised solely in biomedical terms but rather involves social factors such as professionalisation ([1], pp. 131-135). Engel argued that a broadening of the biomedical approach, a new biopsychosocial model, was needed to take account of all these factors 'contributing to both illness and patienthood' ([1], p. 133).

\section{The Presumed 'Overarching Framework'}

In his review of a recent book on the biopsychosocial model by Nassir Ghaemi [2], in The American Journal of Psychiatry, Kenneth Kendler starts with the sentence: "This book is about a very important topicthe overarching conceptual framework of our field of psychiatry" ([3], p. 999).

Whether the biopsychosocial model has this status for the rest of medicine is less clear, given the prominence of biomedicine and its biomedical model. Nevertheless, 'the rest of medicine' is not one thing, and the various medical specialities differ in their relative involvement with the biological, the psychological and the social. Primary care, also known as general practice or family medicine, is well-known to be much involved 
in psychological and social factors, and another clear example is public health. The relevant contrast here is with biomedicine, but biomedicine is not itself a medical speciality, but a particular kind of biological science-based medicine that can be applied across medical specialities, in some more than in others. Although Engel starts his paper referring to the 'medical model', he soon switches to 'biomedical model' and this is the term he uses for the contrast with his new proposed 'biopsychosocial model'. In short it is not only psychiatry but also all the other non-biomedical aspects of medicine and its specialities that apparently require the broader biopsychosocial model.

We will review some of the health science suggesting the need for a biopsychosocial model in the next section, but first let us consider some current major trends in health, disease and healthcare that point to the same conclusion.

Engel was primarily concerned with psychosocial aspects of managing illness within hospitals, complementing the biomedical approach in hospital care. The example he discussed in detail in his 1980 'clinical applications' paper was of myocardial infarction [4]. However, it has become clear in the intervening decades that managing illnesses in hospital is a particular and expensive way of providing healthcare. Illness severe enough to require hospital admission has high burden of suffering and disability, and high costs of hospital care, including biomedical investigations and treatments. It would be better all round to prevent illness altogether, or to detect and manage it earlier to prevent worsening, and also better to provide community and social care where possible to avoid or shorten hospital admissions. Implementing this last strategy involves practical psychological and social factors, such as availability of social supports or social care. The first two strategies, primary and secondary prevention, interact with psychosocial factors such as lifestyle, social capital and health literacy.

At the same time the importance of many of the areas of neglect that Engel conveniently listed under one heading-as shortcomings of the biomedical model-have been ratcheted up by diverse trends including socio-cultural changes, economics and globalisation. The voice of the service user has gained strength from civil rights and general emancipatory social changes; rising costs of healthcare in economically developed countries have focussed minds on containing costs by service reorganisations of diverse kinds; health has become globalised in many ways, such as improving health services in economically developing countries, or 
in the need for international policy to manage epidemics that can now spread more rapidly worldwide.

Other trends since Engel wrote that have also broadened the focus to include more than the biomedical model have to do with changing patterns of population health. Among the greatest achievements of biomedicine have been the identification, treatment and control of infectious diseases. However, and connected, the current burden of ill health in the population now includes many conditions that are not infectious diseases and which have no available complete cure-the so-called non-infectious diseases (NCDs), sometimes also called long-term conditions (LTCs) such as cardiovascular disease, diabetes, recurrent depression and schizophrenia. In addition, as people live longer, for many reasons including biomedical advances, the proportion of the elderly increases, especially in the absence of immigration, and care of the elderly in hospital accounts for a high proportion of healthcare costs. In short, what biomedicine is good at no longer solves a large part of the population health burden and costs, and can contribute to rising costs by keeping us alive longer (thank you at a personal level) but at great expense-to someone, especially the younger generations. What is needed to theorise all these developments is much more complicated than biomedicine or the biomedical model were ever designed for. As well as biomedicine, what is needed is a complex mix of social science, politics, economics, environmental and social epidemiology and psychology — and no doubt more scientific specialities under development.

A further development in the decades since Engel's papers that has added overwhelming weight to the case for a model that can encompass biological, psychological and social factors has been accelerating research on the causes of illness, the basis for primary prevention. The recent research, to be reviewed briefly in the next section, makes two things clear: first, that for many diseases, causes or risks are present from very early on, and second, that for many these causes or risks are combinations of biological, psychological and social. Prospective epidemiological studies suggest that risks for many major illnesses, physical and mental, start early in development, many in childhood, and that risks include social factors such as poverty and other forms of social exclusion, some specific family level factors such as neglect and abuse, and life-style factors such as exercise and diet. Findings on what have come to be called 'social determinants of health' were summarised and publicised for example by Michael Marmot in his 2010 Strategic Review of Health Inequalities in 
England [5]. At the same time, but proceeding largely separately, there have been rapid advances in genetics. Over the past few decades many physical and mental health conditions have been found to have a genetic risk-and genetic risk starts from conception, and interacts with non-genetic factors including but not limited to psychosocial factors of the sort identified in the social epidemiological literature. In short, these sciences combined have produced a whole new dimension of the claim of the biopsychosocial model that conditions of living - as well as biological factors-may affect the onset, presentation and course of an illness.

For all these various kinds of reasons, since Engel wrote his papers some 40 years ago, the biopsychosocial model has become the orthodox overarching model for health, disease and healthcare. It is much cited and taught in healthcare trainings of all sorts and in workshops and ward rounds the world over. In simple terms it recommends to healthcare to take into account all three aspects, the biological, the psychological and the social. It is particularly useful in psychology and social work healthcare professions, and in medical practice that has to deal with the psychological and the social as much as the biomedical, primary care (family medicine) being the clearest example [6], and in-hospital medical training that emphasises the importance of a comprehensive management plan. In all these contexts the biopsychosocial model easily wins, facilitating identification and integration of different aspects of care aimed at different aspects of the patient's life, disease and management. To illustrate further good fit with much current practice, the biopsychosocial model obviously aligns with the rationale of multidisciplinary teams, and with the increasing recognition of the value of the service user's views in providing good and effective healthcare.

Given the prominent status and use of the biopsychosocial model, it is clearly of great importance that the model is clear and robust. At this point, however, there is a very large problem, because there have been increasing charges in the medical literature that in fact the biopsychosocial model-popular and accommodating as it may be-is far from being clear and robust, but is in fact deeply flawed.

\section{But Lacks Content, Validity and Coberence}

Engel's biopsychosocial model has long been criticised for having various kinds of limitation, along with suggestions for improvements (e.g. [7-9]). Increasingly, however, there have been more radical 
criticisms. Such radical criticisms are of two main types: first, that the model lacks specific content, is too general and vague; and second, that it lacks scientific validity and philosophical coherence. Given the popularity of the biopsychosocial model and its presumed status as overarching framework for medicine and healthcare, such radical criticisms signal significant underlying theory problems.

The first broad heading of criticism is well argued by Nassir Ghaemi, a psychiatrist at Tufts, in his 2010 book with the telling title: 'The Rise and Fall of the Biopsychosocial Model' [2]. Ghaemi argues that the model is vague, too general, tells us nothing specific of value, hence is inefficient and sometimes distracting; it 'gives mental health professionals permission to do everything but no specific guidance to do anything' ([2], p. 82). The way Ghaemi tells the story, the biopsychosocial model arose in the context of competing general views about illness, favouring one or other of the social, the psychological/psychoanalytic and the biological. These general views - one might call them ideologies without criticismwere views of the whole domain of illness, offering general accounts, discriminating not much between kinds of case to which they applied and kinds of case to which they did not. Ghaemi interprets the biopsychosocial model as an elegant-if problematic and ultimately unviablesolution to these ideological conflicts: the unseemly turf wars could be ended, a truce could be declared, if all the participants won, if they were not really in opposition at all, but were in fact all true general accounts of illness and healthcare in all their aspects. The problem whether the cause of illness, and hence in theory its prevention and treatment, is biological, psychological or social is solved, because the answer is 'all three' ([10], p. $3 ;[2]$, ch. 6$)$.

It has to be said that this line of thought is not apparent in Engel's main papers $[1,4]$. Ghaemi does however quote a characterisation of the biopsychosocial model from another of Engel's papers consistent with presumed generality: 'all three levels, biological, psychological, and social, must be taken into account in every health care task' ([11], p. $164 ;[10]$, p. 3). This claim Ghaemi understands as meaning that the three levels 'are all, more or less equally, relevant, in all cases, at all times' ([10], p. 3). In these quotes one can see the point of the allegations that the biopsychosocial model is a slogan, too vague to be of any use. And moreover, when pinned down, more than likely just wrong, counter-evidenced exactly by the successes of biomedicine, in which biological factors alone adequately explain diseases and treatments, such as bacterial 
infections and anti-biotics cures. Effective biomedicine is an anomaly for any general claim to the effect that 'everything is biopsychosocial', an obvious point that warrants repetition (e.g. $[2,12]$ ).

So, the charge is that the biopsychosocial model is vague without specific content. If, on the other hand, the model is firmed up to a very general proposition about the general relevance of all three kinds of factors, it is likely to be just false, exactly because of biomedicine. Faced with this obvious enough fact, a possible move is retreat to vagueness, but at the cost of content, as highlighted increasingly by critical commentary.

As mentioned above when illustrating the current important status or aspirations of the biopsychosocial model, Kenneth Kendler opens his review of Nassir Ghaemi's book with the statement that its topic is very important, the overarching conceptual framework of psychiatry ([3], p. 999). In his review Kendler goes on to quote Ghaemi's negative conclusion, 'The BPS model has never been a scientific model or even a philosophically coherent model. It was a slogan...' ([2], p. 213), and comments: 'While the reader may think this a little harsh..., I think he is substantially correct in this assessment' ([3], p. 999). On the other hand, Kendler ends his review with a reminder of the importance of the biopsychosocial model as a teaching tool in family medicine, concluding: 'While I agree with Ghaemi that the Biopsychosocial model has been a failure as a scientific paradigm, it probably continues to serve a useful clinical and teaching function in psychiatry and medicine' ([3], p. 999). Kendler correctly identifies the major tension here: the biopsychosocial model is a useful tool for clinical and teaching functions, but apparently lacks scientific validity and philosophical coherence.

But then probably all cannot be problem free on the teaching front either. Here is Chris McManus, Professor of Psychology and Medical Education at University College London, reviewing an earlier edited book on biopsychosocial medicine in The Lancet ([13], p. 2169):

Biopsychosocial medicine's challenge is to transcend the vague, aspirational inclusivity of its name, and to create a model that truly merits being called a model, and is properly explanatory and predictive ... Arm-waving and the inclusion of everything ultimately says and does little of practical consequence.

Ghaemi, Kendler and McManus all basically agree in their negative assessments of the biopsychosocial model. 
Given the popularity of the biopsychosocial model, its use in teaching and the clinic, its presumed status as the overarching framework for psychiatry and perhaps for medicine generally, such authoritative negative assessment signals significant problems at the conceptual foundations.

We believe that these two kinds of charge put to the biopsychosocial model, querying its content, validity and coherence, are cogent, but can be met. What they signal is not the end of the model-witness the fact that it persists, for good reasons already indicated-but the need to rethink and reinvigorate it. The answer to the content problem, we suggest, is that the content lies in scientific and clinical specifics, not generalities. This is proposed in the next section, beginning with a brief review of the emerging basic and clinical science supporting the biopsychosocial model. This response to the content problem, however, immediately raises the question: if the content of the biopsychosocial model lies in specifics, what is the point of the general model? We suggest that this question relates to core scientific theory, at the place where it merges into philosophy, and is therefore here that the problem of scientific validity and philosophical coherence is to be addressed. We define this problem in Sect. 1.3, and address it in detail through subsequent chapters.

\subsection{Locating the Content of the Biopsychosocial MODEL}

\section{Emerging Evidence of Psychosocial Causation}

Just as the biomedical model is of interest because of the substantial and well-established evidence base of biomedicine, so the biopsychosocial model warrants attention insofar as there is evidence of psychological and social as well as biological factors in health and disease. There has been an accumulation of such evidence in recent decades, and before moving the main theoretical argument forwards, we pause to review some of it.

This review carries a health warning! It is uncritical and unsystematic; we have usually not distinguished strength of evidence of the studies cited below (uncontrolled to randomised controlled and replicated), nor commented on other aspects of methodological strengths (such as sampling strategies and sample size), nor on conflicting and uncertain results, nor have we employed a systematic literature search strategy. Many of the papers cited are reviews, more or less systematic. The purpose here is only to orientate the unfamiliar reader to wide range of 
research that has supported on-going interest in the interplay of biological, psychological and social factors in health and disease and hence the biopsychosocial model.

Over the past few decades the picture that has emerged for causes of disease onset, especially for the non-communicable diseases, also known as the LTCs, is one of complex, multifactorial causation, involving many risk factors of relatively small effect, affecting multiple outcomes. The recent research on social factors as causes or risks for poor health-the so-called 'social determinants of health'-is probably the most well-known, new face validation of the need for a broad biopsychosocial model. Among the most influential social epidemiological research programmes are the Whitehall Studies of British civil servants, led by Michael Marmot [14-16]. These longitudinal cohort studies found robust correlations between variance in incidence for a wide range of health conditions - coronary heart disease, premature mortality, some cancers, lung disease, gastrointestinal disease, depression, suicide, sickness absence, back pain and general feelings of ill-health-and civil service grade. The social gradient in health-the correlation between indices of social status and health outcomes-is now well-established; much is now known about the social determinants of health $[17,18]$, and something like the biopsychosocial model has to be invoked in order to comprehend it. As typically for epidemiology, most findings on the social gradient in health come from association studies only, retrospective or prospective. Establishing causation is more complex, using such as controlled cohort studies, natural experiments or animal models.

Other large research programmes have investigated associations between adverse psychosocial exposure in childhood and later health outcomes. A landmark programme is the Adverse Childhood Experiences Study (ACE Study) in the United States, carried out by Kaiser Permanente and the Centers for Disease Control and Prevention. The ACE study has demonstrated associations between adverse childhood experiences, such as physical and emotional neglect and abuse, and a large range of physical as well as mental health outcomes (e.g. [19]).

Lifestyle factors, comprising behaviours and associated beliefs, attitudes and values, have been increasingly implicated as risks, or conversely as protective factors, for a wide range of physical health conditions $[14,18]$. For example risk factors for some cancers and cardiovascular disease include such as smoking, alcohol use, diet, exercise and chronic stress. Lifestyle factors can be covered under the same heading as social 
factors, or separately. Either way, lifestyle factors interact strongly with social context, reflecting Engel's insight that the person is essentially within a social context: diet for example, depends to some extent on choice, but also on what is available and affordable; stress- to be considered in Chapter 4-depends on individual characteristics but also on task demands and available resources.

Lifestyle and psychological factors can be distinguished: the former are behavioural, while the latter, such as beliefs, attitudes and values, are mental. At the same time they are closely linked. One reason is that psychological factors motivate lifestyle, but there is also a general linkage between our psychology and our behaviour, namely, that we respond to reality at it appears to us, at any given time, to be. We pick this up as a theoretical point in more detail later, in Chapter 3 (Sect. 3.1, heading "Mind Is Embodied"). In the present context it appears in evidence suggesting that it is not objectively measured social status but social status as perceived, so-called 'subjective social status' that accounts for more of the variance in health outcomes (see e.g. $[20,21])$. This interesting finding becomes part of the complex jigsaw puzzle of biopsychosocial aetiology.

Over the same past few decades that evidence for psychosocial factors in health and disease has been accumulating, so also has evidence of genetic effects. For some health conditions such as Huntington's chorea, and some cancers, there are massive genetic effects, but for the majority of health conditions, the proportion of population variance attributable to genetic influence is much less than $100 \%$, the picture being rather of relatively small effects of multiple genes, with the remaining variance attributable to non-genetic, environmental factors. Combining these broad kinds of research programmes presents a biological-psychological-social and-environmental picture, and new epigenetics is likely to help explain how the various kinds of factor interact. These issues are taken up in Chapter 3, Sect. 3.4.

Post-onset course of disease raises different causal questions: what are the processes determining course, for example, progression, stability, fluctuation or recovery? Treatment effects are a special case, assessed using a range of designs including randomised controlled trials. There has been accumulating evidence from randomised controlled treatment trials since the late 1970s of treatment effects of psychosocial interventions on some mental health conditions. Among the first was a randomised controlled trial of cognitive behaviour therapy for depression 
published by Beck et al. [22] showing effectiveness, but further, the same effectiveness as for anti-depressant medication. In effect this trial showed that a psychological intervention could achieve the same result as a biomedical intervention, and it paved the way for accelerating developments of tested psychological treatments for a wide range of mental health conditions and the translation of these into national health service provisions. There are complications, as always, for example, as to the extent to which psychological therapy outperforms pill placebo control, but the principle that some psychotherapies help some mental health conditions has been established (e.g. [23]).

The position is different with physical illnesses. Put strongly, there is a glaring gap in the evidence for the biopsychosocial picture as a whole, namely, absence of persuasive evidence of psychosocial treatment effects on the course of major physical illnesses. There is no clinical trial that finds effects of psychological therapy on physical illnesses such as, say, diabetes, cancers, cholera or advanced cardiovascular disease. We just wish to make the point that no psychotherapy or any other kind of psychosocial intervention turns around such disease processes once established, and this is a major apparent fact that needs to be taken into account in discussing the relative merits of the biomedical model and the broader biopsychosocial model. This is linked to the fact that for the many conditions that are managed biomedically in acute hospitals, successfully in some cases, there need be no special interest in the broader biopsychosocial model, and any advocate of the broader model has to accommodate the fact that whatever other significant roles they may have, psychosocial factors apparently make no difference to the course or treatment of major physical illnesses.

That said - and we intend it to be a big that - there is emerging evidence that psychosocial factors may be implicated in the prognosis of some among the very large range of medical conditions. For example: breast cancer (e.g. [24]), atopic disease, generally [25], including for asthma [26]; HIV [27-29] and musculoskeletal disorders (e.g. [30]). In addition, psychosocial factors have been implicated in outcomes of surgical procedures, for example, chronic pain [31]; lumbar and spinal surgery [32-38]; liver transplant (e.g. [39]) and coronary artery bypass (e.g. [40-42]). In addition, there is evidence for psychosocial factors in wound healing $[43,44]$, and extent of fatigue after traumatic brain injury [45]. Psychosocial factors have also been implicated in responses to other interventions for medical conditions, such as inpatient 
rehabilitation for stroke patients (e.g. [46]), and effects of hospitalisation on older patients (e.g. [47]).

Reference to psychosocial factors affecting course of medical and post-surgical conditions is not intended to be read as either conclusive or general. Many studies on this general topic are of associations only, and there are many mixed results. Hence the subtitle of this section, 'emerging evidence', and the explicit qualification of specificity to particular conditions and stages. Further, absence of reports of psychosocial effects on medical conditions, while it may suggest simply that the research has not yet been done, may also indicate that results have been negative and unpublished, and further back in the clinical research sequence, that clinicians have not seen evidence warranting case study research reports, progressing to cohort studies, and so on. This takes us back to the point made first, that some major medical conditions, such as the primary dysfunction in diabetes, or advanced cancers, or advanced cardiovascular disease, appear to be influenced exclusively by biological factors, impenetrable to psychosocial processes and interventions, and in some cases also unresponsive to biological interventions.

An old-fashioned way of making this point is to say that the mind cannot control biological processes such as abnormal cell growth. In the old dualist framework, however, the mind couldn't really control anything material, not cell growth, but not arms and legs either, so the discriminating point got lost in the metaphysics. In the new post-dualist scientific framework, to be outlined in Chapter 3, the 'mind' is not immaterial, not causally impotent, but more a matter of the central nervous system regulating some internal systems as well as the behaviour of the whole in the environment, and in these terms there are researchable differences between what the central nervous system can control and what it cannot. Extent of control may be modifiable, subject to individual differences, training and practice, but we know now that even at its best the central nervous system is not an omnipotent controller: there are places and processes that CNS signalling pathways do not reach, for example, cell growth, linked to the fact that the cells are very basic, similar in humans as in yeast; nor does the brain control the journey and final resting place of an embolus, and a long list of other biological processes and outcomes, benign or catastrophic. And this list can be contrasted with a list of biological processes and pathways that can or might have CNS involvement, as suggested by studies cited above. These issues and options only open up, however, in a new post-dualist metaphysics 
and biopsychological scientific paradigm, which are large themes to be addressed through the book. For now, we return to review the findings on biopsychosocial factors.

The next point to note is that, even for those physical health conditions that are unaffected by psychosocial factors, generally or at specific stages, still such factors may be relevant to clinically significant aspects of disease progression and management. These are factors such as access to treatment, participation in the recommended treatment regime, associated pain, psychological/mental health complications and health-related quality of life. Some details and literature as follows:

Access to healthcare is an obvious heading, covering diverse factors such as public health screening to ensure timely detection, health literacy, availability, accessibility and affordability of care, and quality of care-all factors heavily dependent on personal, class and state economics, associated therefore with the social gradient in health [5, 48, 49 and e.g. 50].

Acceptability of/participation in the recommended treatment regime. Psychosocial factors are associated with medication non-adherence, for example, following acute coronary syndrome [51], in haemodialysis patients [52], in youth with newly diagnosed epilepsy [53]. One systematic review of study of psychosocial factors predicting non-adherence to preventative maintenance medication therapy produced a negative result and call for more research [54].

Psychosocial factors in pain. Pain as an important phenomenon and concept spanning the biopsychosocial and will be considered further in Chapter 4. Clinical studies implicating psychosocial factors include: in chronic pain $[55,56]$ and in pain associated with specific conditions/ sites, such as multiple sclerosis [57]; musculoskeletal pain [58, 59]; low back pain $[60,61]$; spinal pain [62]; chronic prostatitis/chronic pelvic pain syndrome in men [63]; osteoarthritis [64]; cancer-related pain [65] and pain after breast cancer surgery [66].

Psychological/mental health complications of medical conditions. This is an increasingly recognised issue, with implications for quality of life (on which more below), social impairments and costs, in primary care [67], in LTCs [68] and in oncology $[69,70]$. Accumulating clinical experience and research has led to a new UK NHS policy directive requiring psychological therapy services to be integrated into physical healthcare pathways [71].

Quality of life. There is a substantial literature on psychosocial factors and health-related quality of life in medical conditions, for example, in 
patients with haematological cancer [72]; children with myelomeningocele [73]; colorectal cancer survivors [74, 75]; myocardial infarction [76]; after hip fracture in the elderly [77]; newly diagnosed coronary artery disease patients [78]; adults with epilepsy [79], and after surgery [80]; and youth-onset diabetes myelitis [81].

Accumulating health data of the sort indicated above implicating psychosocial as well as biomedical factors, taken together, cover a large proportion of population health and health service provision in clinics and hospital beds. In other words, they are massively important, looked at in terms of population health, individual suffering, or economic costs; they are not a side-issue compared with conditions or stages of conditions that involve biological factors alone.

The psychosocial data have accumulated over the past few decades and have vindicated Engel's proposal of a new model for medicine and healthcare. Engel was ahead of the game, and the popularity of his model is explained at least partly by the fact that it appeared as a ready-made framework for accommodating the emerging evidence of psychological and social causal factors in determining health and disease.

In these terms its clear that we need a biopsychosocial model of the sort that Engel anticipated, but one that can meet the criticisms reviewed previously that the model, at least as we currently invoke it, has serious problems including lack of content and incoherence. We propose in the next section a solution to the content problem, based, as would be expected, on emerging findings implicating psychosocial as well as biological factors of the sort outlined above. As to the coherence problem, this will involve theorising the categories of 'biological', 'psychological' and 'social' in such a way that they can interact in health and disease. This theorising will occupy the rest of the book. One strand was already mentioned earlier in this section: the old dualism between mind and body is replaced by a partial and to some extent negotiable interaction between the central nervous system and other biological systems. This theory-shift will be taken up in Chapter 3, along with the proposal that the primary concept of the psychological is embodied agency, with implications for health, drawn out further in Chapter 4: a person's psychological health depends on the development of a viable enough sense of agency, while conversely, if agency is seriously compromised, such as in conditions of chronic stress, their mental health is liable to suffer, and so also, via complex biopsychosocial pathways, is their physical health. 


\section{The Scientific and Clinical Content Is in the Specifics}

Let us pick up the line of argument in this chapter. The biopsychosocial model is much invoked, with claim to be the overarching framework for psychiatry and other branches of medicine such as primary care, perhaps for medicine generally. It has however been severely criticised, for being vague, without scientific or clinical content. Here is our suggested remedy: the scientific content and clinical utility of the biopsychosocial model is not to be found in general statements, but rather is specific to particular health conditions, and, further, specific to particular stages of particular health conditions. We provided above a brief, non-systematic, non-critical review of some of the emerging evidence of involvement of psychological and social as well as biological factors. All the evidence refers to particular health conditions or classes of conditions, and particular stages: risks for onset, post-onset course, including under treatment, adjustment and quality of life.

At the time Engel wrote there was not much evidence of causes of diseases and treatment effects, with important exceptions in the case of some major infectious diseases. But especially, compared with now, relatively little was known, though much was speculated, about the role of psychosocial factors in health and disease. Since then, in the intervening decades, there have been massive new research programmes, not only in biomedicine, but in clinical psychology, neuroscience, social epidemiology and genetics, and in treatment trials, pharmacological and psychological. Much more is now known about the causes of diseases and about possible disease mechanisms, with associated technologies for prevention, early detection and treatment. This broad evidence base has led in turn to treatment guidelines for specific conditions, to the whole apparatus of evidence-based clinical care, to be used alongside a thorough assessment of the individual case. Much of the science and clinical management is now psychological and social as well as biological. Given this situation as it is now, the scientific and clinical content of the biopsychosocial model is in the specifics, not in a 'general model'. Much the same, by the way, can be said of biomedicine and its associated biomedical model: medicine, whether biomedical or biopsychosocial, deals with complex, specific systems.

The proposal that the content problem is resolved by focussing on specifics not generality also helps explain how the problem arises. In brief, it is because the specifics are too many and too complex, that some 
shorthand, vague gesturing, is sometimes useful. The basic and clinical sciences of the past few decades invoke very many kinds of factors in their models: biological factors-biological systems, including neural systems and genetic mechanisms - but also psychological factors-such as temperament, personality, lifestyle, adjustment, quality of life-and also social determinants of health and disease-variants on social inclusion or exclusion-together with the implication that all these things interact over time, in the course of life and the illness, in complicated and barely understood ways. So, on occasions when the question arises, for example in clinical consultation or healthcare education systems: 'and what are the factors involved in this or that disease, or individual presentation?'- the quick answer would be: 'it's all biopsychosocial', or 'it's as the biopsychosocial model says'. The full answer is much longer, in the systemic reviews of the epidemiological and clinical sciences, treatment trials and clinical guidelines-but this full story does not fit in a ward round or clinical consultation; it more makes up years long healthcare educational training programmes. As workable compromise, the brief throwaway- 'it's all biopsychosocial' could be expanded into something more informative along these lines: 'In this condition there are possibly (or probably) biological, psychological and social factors involved, in some stages, some of which have been identified, with more or less confidence, combining together in such-and-such ways, though interactive causal pathways are bound to be complex and (typically) not yet well understood - the details of what is known and hypothesised about the condition to date is in the literature/is among the topics in one of your teaching modules'.

Such an answer, and the science it refers to, is about a particular health condition, such as diabetes, or depression. In this sense there are multiple specific biopsychosocial models: a model for diabetes, depression, cardiovascular disease, schizophrenia; and so forth. Further, much depends on what stage or what aspect of a particular condition we have in mind, whether pre-onset aetiological risks for onset, or post-onset course, involving many issues including maintaining factors, treatment responses, complications, psychological adjustment and factors affecting quality of life. The factors involved in these various stages and aspects typically differ within any particular condition, and especially they differ in the relative involvement of biological, psychological and social. For example, social epidemiological studies suggest that social factors as well as biological are implicated in the aetiology of a wide range of health 
conditions, such as cardiovascular disease and depression, while treatment might not be so, as in surgical intervention for advanced cardiovascular disease, or pharmacological therapy for depression. This latter is typically best combined with psychological therapy, which might also be indicated to aid adjustment and recovery of quality of life following cardiovascular surgery. In short, there is need for much discrimination between what conditions we are talking about, what stages of conditions and questions of interest in each. This is the specificity and complexity of diseases and therefore of the science and its models.

We stress here that we mean no implication that particular diagnostic categories are valid once and for all, or optimal in terms of explanation or prediction. Rather, they simply represent the current consensus state of clinical practice and clinical science and are liable to revision, to subtyping or supra-typing, or to replacement altogether. The proposal is that biopsychosocial medicine, like biomedicine, is applied to specific health conditions, in terms of which the science at any one time is conducted; but identification and classification of these conditions are subject to change.

In brief, our proposal is that, while the biopsychosocial model can sometimes appear as vague hand-waving, absent any scientific or clinical content, this is because we are looking for content in the wrong place, in the general model, rather than in the epidemiological and clinical science literatures about particular conditions. This proposal, if accepted, solves the content problem.

On the other hand, that said, such a solution immediately raises a still more radical problem for the biopsychosocial model: if it's all about specifics, what is the point of having a 'general model'?!

\section{So What's the Point of a 'Geneval Model'?}

Engel wrote about the biopsychosocial model in a way that suggested it had scientific content and clinical utility. His 1980 paper [4] was on clinical applications of the biopsychosocial model, the main example being myocardial infarction, consistent with the reasonable expectation that the model specified biopsychosocial causal pathways in particular conditions and hence could guide clinical practice. However, the position regarding what is known in the science has radically changed in the intervening decades, and now, as argued in the preceding section, the 'general model' is probably now not the place to look for causal pathways, clinical 
applications and treatment guidance, which are rather to be found in the health science literatures.

One possibility in the circumstances, as the evidence accumulates, is that the general model might summarise the evidence for all the health conditions, along something like the following lines: "Psychological and social factors as well as biological factors (each of these being of many different kinds) are relevant to all health conditions and all healthcare, though they vary in their relative contributions, depending on the condition and the stage of the condition, between $0-100 \%$, or mostly between, say, $20-80 \%$ - summing to something like $100 \%$ ".

However, while such a general proposition might be true, give or take some percentage points, it clearly has no or not much content, or use, in for example shaping guidance about prevention or clinical management. It is certainly less informative and useful than the full picture for a specific health condition. It is true that a general statement of the model such as the above can serve to remind us and our students to keep one's mind open to the range of biopsychosocial factors, but the treatment guidelines and the science behind them already now say this, if applicable, and there is limited gain from repeating the fact-vaguely. Used in this way, the model runs the risk of being, minimally, a bucket to throw research findings into, convenient for hand-waving purposes. As for basic scientists and clinical trialists, they investigate the causes, mechanisms and treatment of cardiovascular disease, depression, and so forth; with definitely or probably not much need or time for a 'general model'.

So what is the point of a general model? Perhaps as a theory of health and disease. But the line of thought we are pursuing is exactly that health and disease are not one thing, or two things, but each many things, depending which system within us is functioning well or poorly. Even so, the general picture still matters when the whole of health is in question, for example in estimating and projecting population health, planning and prioritising health services and research funding, on treatment, primary or secondary prevention, planning syllabuses for health education, or modelling linkages between health outcomes and outcomes in other sectors such as education, productivity or national happiness. Clinicians, patients and researchers may well be concerned with specific conditions, but for many other purposes views of the whole are required. The concept of biomedicine arose in the recognition that many effective health technologies had in common that they relied on biological factors only, 
notwithstanding complex biopsychosocial presentations. Such a concept then drives further lines of enquiry, investigating biological factors in other conditions. An analogous point applies to the biopsychosocial model. A related point is a need for a framework to organise accumulating research findings, to recognise emerging patterns, to identify what is known, with more or less certainty, and what is not known. This applies to specific conditions such as cardiovascular disease, or addictions, but it also applies across health conditions as a whole.

There are many purposes for a general model and accordingly many ways of constructing such a thing. We focus here on the general biopsychosocial model as a core philosophical and scientific theory of health, disease and healthcare, which defines the foundational theoretical constructs - the ontology of the biological, the psychological and the socialand especially the causal relations within and between these domains.

While the details of the relative roles of biological, psychological and social factors in specific health conditions, at particular stages, are matters for the health sciences, the general, or core, biopsychosocial model is more of an exercise in the philosophy of science-in this case, philosophy of biology, philosophy of mind and social theory, but especially as applied to health and disease. These philosophies are especially relevant in the present case, because there is massive historical baggage, carried in the long history of physicalism, dualism and reductionism, that makes biopsychosocial ontology and causation deeply problematic. This whole problem area needs rethinking and reconceptualising in the light of current scientific paradigms and philosophical theory.

\subsection{The General Model: Biopsychosocial ONTOLOGY AND INTERACTIONS}

\section{Defining the Problem}

Engel was well aware of the philosophical problems involved in the shift from the biomedical model to the biopsychosocial. This is how he characterises the biomedical model ([1], p. 130):

The biomedical model embraces both reductionism, the philosophic view that complex phenomena are ultimately derived from a single primary principle, and mind-body dualism, the doctrine that separates the mental from the somatic. Hence the reductionist primary principle is physicalistic; 
that is, it assumes that the language of chemistry and physics will ultimately suffice to explain biological phenomena.

The biomedical model so understood, as based on these philosophical views, is antithetical to any extension to a biopsychosocial model, and conversely, if the biopsychosocial model is to be viable, it has to overcome the challenges they pose. This is well recognised by thoughtful commentators on the biopsychosocial model, including those, quoted previously, who criticise the model for its hand-waving tendencies. Here is Chris McManus in his review for The Lancet cited previously ([13], p. 2169):

The challenges for the Biopsychosocial Model involve reductionism, dualism, mechanism, methodology, and causality. The psychological and the sociological are ineluctably phenomena of the mind, and the reductionist challenge is how to integrate the mental with the cellular, molecular, and genetic levels at which biomedicine now works.

Ken Kendler in his review quoted earlier, goes on to identify the philosophical issues relevant to the biopsychosocial model and the work that needs to be done ([3], p. 999):

[These are] the issues that the Biopsychosocial model at least seemed to be addressing - how to integrate the diverse etiologic factors that contribute to psychiatric illness and how to conceptualize rigorously multidimensional approaches to treatment. [There is] a range of exciting recent developments in the philosophy of science on approaches to complex biological systems, which are quite relevant to these issues... [which] examine scientific approaches to complex, nonlinear living systems and explore various models of explanatory pluralism, from DNA to mind and culture....

The importance of understanding causal interactions between kinds of factors is also highlighted by Dan Blazer in his review of Nassir Ghaemi's book [82] (p. 362):

[There are] emerging efforts across all of medicine to integrate biological, psychological, and social factors in the exploration of the causes and outcomes of both physical and psychiatric illnesses.... These efforts are not eclectic but transdisciplinary, efforts which are leading to a much better understanding of how biological, psychological, and social factors interact through time. 
Both Kendler and Blazer identify the current challenge of constructing a coherent view of causation in health and disease that can encompass biological, psychological and social factors. Kendler refers to recent philosophical developments and Blazer to emerging efforts in health sciences, both implying a historical dimension and that something new needs to happen and is happening, at a conceptual level as well as a scientific level.

Engel's characterisation of the biomedical model, a reasonable one in the 1970s, had it supposing that only the biological exists, or is alone causal in health and disease, and it exists as physics and chemistry, with the same principles or laws of causation. The ontology was flat and reductionist: nothing new grew out of the basic physics and chemistry, and any other domain with aspirations to be causal had to be ultimately reduced back to the basics. To construct an alternative to this set of assumptions it is necessary to envisage ontology and causal relations other than, and in some metaphorical sense 'above', those in physics and chemistry. Engel proposed systems theory for this purpose, and as we shall consider in later chapters, we think this is fundamentally the right way to go.

A systems theory approach in fact already underlies the solution to the content problem we proposed in the previous section. We proposed in Sect. 1.2, heading "The Scientific and Clinical Content Is in the Specifics", that the content is to be found in the science and clinical guidelines on specific health conditions. This is the indicated move because specific systems are distinctive, with their own distinctive functions, operating principles and vulnerabilities to dysfunction, which therefore have to be modelled separately. Healthcare science along with other systems sciences, essentially deals in specifics. This has always applied to biomedicine, which deals with particular biological systems. It also applies in psychology, which deals with particular psychological systems, such as motivation and fear, and in clinical psychological theoryfor example, cognitive behaviour therapy has specific models for such as depression, obsessive-compulsive disorder and panic disorder.

The question arises then: what is the core theory linking together the various applications to specific systems? For biomedicine, in the way that Engel characterised it in the 1970s, the core theory was that biology is physics and chemistry, and biological causation is physico-chemical causation. This has changed; it is no longer true of current biomedicine; this is the topic of the next chapter. The core theory underpinning cognitive behavioural therapy, as stated by its founders Aaron Beck and colleagues [22] (p. 3) is startlingly brief, that cognitions cause affect and 
behaviour. However, even this brief statement of the core model does crucial work: it highlights the working assumption that intervening with cognition is the way to modify troubling emotions and behaviour, and it links together the various types of cognitive behaviour models for diverse conditions. Even in the absence of explicit theory of causation, there can be evidence of causal connection from well-designed treatment trials, but also, in this particular case there is a long and respectable history of the cognitive theory of the emotions and the philosophy of practical reason that provides conceptual familiarity for working purposes.

The contrast here is with the biopsychosocial core model: there is no long and respectable history of philosophy and science theorising causal interactions between the biological, the psychological and the social. To the contrary, the history since the beginnings of modern science in the seventeenth century consists of assumptions and arguments that psychological and social causation are impossible or even incomprehensible, that there is no distinctive biological causation either, over and above physics and chemistry. The historical background is entirely hostile to the whole idea of biopsychosocial causal pathways, and there is therefore a need for an explicit theory as to what the new idea is. It is this, we propose, that is the purpose of the general biopsychosocial model; in short, to theorise biopsychosocial causal interactions.

We review some main relevant historical background below, under the heading "Prejudicial Theory: Physicalism, Reductionism, Dualism". First, in the next section, we consider how the search for biopsychosocial theory is not only of interest to reworking a model proposed some 40 years ago, but has arisen in the health sciences themselves.

\section{Biopsychosocial Data in Search of Theory}

The emerging evidence of psychosocial causation in health and disease of the sort briefly outlined in Sect. 1.2, comes from studies using empirical methodologies that have been developed and applied substantially since Engel wrote his papers on the biopsychosocial model. Prior to these new research methods, there was little or no demonstrated evidence of psychological and social causes of physical health conditions. Their effects were not as plain —as massive - as those identified by biomedicine, as for example effects on incidence of cholera of drinking contaminated water from a particular pump, or recovery following treatment by antibiotics. 
In the absence of a significant body of evidence of a causative or curative role of psychological and social factors in particular diseases, claims as to their importance were bound to have an uncertain status: were such claims meant to be general, to apply to all conditions, meant to be obvious, or based on prejudice or expert consensus-or specific to particular conditions? In the absence of much evidence, the appearance of ideology was inevitable - and this is one of the key points behind Ghaemi's critique of Engel's biopsychosocial model [2], considered previously (Sect. 1.1). However, the amount of evidence and most importantly the type of evidence bearing on these issues has changed radically in the 40 years since Engel proposed the model. We refer to use of novel statistical methodologies and associated study designs that are sensitive to multiple factors, relatively small, partial causal influences, usually called risk factors, contributing in some way to a complex nexus of causation associated with a particular outcome of interest. The development of these new methodologies was based on nineteenth-century conceptual work on the scientific demonstration of causation, and early twentieth-century work in the theory of statistical inference.

Much of the intellectual work clarifying the scientific methodology required for the determination of causes was done by J. S. Mill in his $A$ System of Logic [83]. Hume [84] had seen that causality is linked to generality, that the statement 'A causes B' implies that events of type A are always followed by events of type B. This implies also that knowledge of causes enables prediction, that the next A will be B. Mill saw, however, that in practice what is observed on any one occasion is not simply an event of type A being followed by an event of type B, but this conjunction in a complex of circumstances, $\mathrm{C}$. To establish a causal link between $\mathrm{A}$ and $\mathrm{B}$ the possible confounding effects of $\mathrm{C}$ have to be determined. This involves observing the effects of $\mathrm{C}$ without $\mathrm{A}$, on the one hand, and $\mathrm{A}$ without $\mathrm{C}$ on the other. These principles, elucidated by Mill as the 'methods of agreement and difference', underlie our modern idea of controlled experimentation.

Robert Koch's pioneering work in microbiology in the closing decades of the nineteenth century made four postulates as methodology to determine the causal relationship between a microbe and a disease, applied to the aetiology of cholera and tuberculosis $[85,86]$. Koch's postulates tapped similar principles to Mill's, including assumptions of generality and isolation of the suspected active causal ingredient'isolation' here requiring cutting edge technology of the time. 
Interestingly Koch himself recognised that there was a problem with the generality requirement, which takes us on to the next main point.

Hume, Mill and Koch supposed that causality is general-applies to 'all'. However, in practice in the lifesciences, medicine, psychology and the social sciences we rarely find universal generalisations, but rather partial ones, of the form: $\mathrm{A}$ is followed by $\mathrm{B}$ in a certain proportion of observed cases. One function of a universal generalisation is to license the simple inductive inference: the next observed A will be followed by $B$. In the absence of a universal generalisation, the problem is to determine the probability of the next $\mathrm{A}$ being followed by $\mathrm{B}$, given that the proportion in the sample so far observed. This is the problem for the theory of statistical inference, developed in the first decades of the twentieth century.

The theory of statistical inference is a necessary condition of being able to detect reliable small correlations between two factors, between say amount of daily exercise and cardiovascular function at a later time. The implications of correlations being small-much less than 1 and not much above 0 -is that other factors are at work, signalling the need for investigation of multiple factors associated with the particular outcome of interest. Investigation requires a group study in which each factor is each measured and their association or correlation with the outcome computed. Analysis of variance, ANOVA, is one class of statistics that can be used for such purposes: there is an outcome of interest, the so-called dependent variable, and several independent variables, hypothesised to effect it. For example, the dependent variable may be onset of cardiovascular disease by 40 years, the independent variables are individual characteristics such as weight, diet, smoking, exercise, multiple deprivation index, family history as assumed proxy for genetic vulnerability, and the results of the ANOVA will quantify the amounts of variance in outcome and hence risk attributable to these several factors, alone or in combination. Other classes of statistical analyses can be used, more or less closely related, depending for example on the nature of the variables (e.g. categorical or continuous) and on study design (e.g. cross-sectional or longitudinal). Use of such methods has become pervasive in the human sciences in the past few decades, reflecting the fact that the phenomena are complex with multiple causes; instances when a single variable completely explains a phenomenon (accounts for all or most of the variance) are rare.

Naturalistic studies of populations in the first instance establish correlations only, and further investigation is needed to establish causation, 
using or approximating to experimental methods of the sort elaborated by Mill and Koch. Experimental designs for establishing causation typically involve at least two groups, assumed to be identical in relevant respects-either known or suspected to affect the outcome of interest-except for one factor, the factor of interest. Differences of outcome between the two groups are then attributable to the factor of interest in accordance with Mill's method of difference. The factor of interest is often a treatment - an 'intervention'. Confidence in the assumption that the two groups are otherwise identical in relevant respects is critical in these methodologies, and there are many methods of 'matching' groups to achieve this. The philosophical justification for regarding controlled designs as the appropriate methodology for establishing causation such as treatment effects has been argued elsewhere [87]. The gold standard for maximising this confidence-the true experimental design-is taken to be randomisation, with sufficiently large numbers, such that possible confounding causal factors can be reasonably assumed to be distributed equally between the groups. Quasi-experimental designs, such as matching cohorts, can also be used, though the confidence that unknown confounders are equally matched is less. There are also 'natural experiments' (see e.g. [88]), and sometimes the background base rates absent the putative cause are safely assumed.

If we establish that a universal correlation is causal, the finding can be expressed as A causes B. Typically in the life and human sciences, correlation between factors is partial-variation in A accounts for only part of the variance in outcome B-in which case the correlation can be expressed as: A raises probability of $\mathrm{B}$, in some specified degree depending on the size of the correlation. If $B$ is a harmful outcome, such as a poor health outcome, this is often expressed: A raises risk of $\mathrm{B}$, in some specified degree.

Population studies of risk factors for the onset of disease cannot use randomisation designs, plainly for ethical reasons, and are generally limited to more or less refined quasi-experimental methodology. Experimentation is left to animal studies. Treatment studies of the effect of an intervention on the course of a disease once onset can use randomisation designs-again subject to ethical constraints.

The new study designs and analytical methodologies showed effectstypically small - of psychological and social factors. The same methodology of course can show the importance of biological factors of small effect, such as genetic and epigenetic effects. 
Relevant to our main theme, however, we can note that while these new study designs and statistical methodologies are well theorised, as is the determination of causes by experimental and related methods, they provide in themselves no theory of the factors indexed by the variables and no theory of causal mechanisms linking them. They can provide evidence of biopsychosocial causal connections, but no theory about them. This absence of theory is important because of the historical background of dualism and physicalist reductionism, noted at the beginning of this section (under the heading "Defining the Problem"), that would exclude any distinctive forms of biological (as opposed to physico-chemical), psychological and social causation. We review some main points of this historical background next.

\section{Prejudicial Theory: Physicalism, Reductionism, Dualism}

Engel's characterisation of the biomedical model-quoted at the beginning of this section, uses a few key technical terms: reductionism, physicalism and physicalist reductionism (Engel uses 'physicalistic'). These terms refer to complex and controversial concepts with long histories, and we will use working characterisations as follows:

Physicalism is the view that everything that exists is physical. This is an ontological statement-about what there is. It has often been combined with the corresponding statement about causation: that all causation is physical, covered by physical laws. On the assumption that chemistry is basically physics, physicalism can be expressed in terms of physics + chemistry. The contemporary philosophical literature on physicalism is substantial (for recent review see e.g. [89]). Working around physicalism is necessary to establish a biopsychosocial model and is addressed in more detail in the next chapter.

Reductionism has various meanings. In one of the senses used by Engel in his characterisation of the biomedical model, quoted at the beginning of this section, it is a scientific claim that complex phenomena have a main cause of a particular type. In the medical context, reductionism in this sense would claim that there is a main cause of one or other kind: biological (e.g. an infection or lesion), or psychological (e.g. unconscious conflicts, or maladaptive cognitive style), or social (e.g. social exclusion; labelling). There is also a philosophical or metaphysical doctrine of reductionism, deriving from physicalism, as follows:

Physicalist reductionism follows from the strong version of physicalism which has ontology and causation as all a matter of physics. It is a 
strict consequence for other sciences, such as chemistry, biology, psychology and social science: either they are true causal sciences, in which case they must ultimately reducible to the concepts and laws of physics; or, otherwise, they are pseudo-sciences, or at least, 'sciences' that do not deal with causation. Physicalist reductionism so understood is a philosophical or metaphysical doctrine in the sense that it is known or alleged a priori; it is not based on scientific research, but rather prejudges what there is to be discovered. Physicalist reductionism along with its roots in physicalism is taken up in the next chapter.

Physicalism has a long history, its roots lying in what historians of science refer to as the 'mechanisation of the world picture' in the seventeenth century [90-92]. This involved defining the primary qualities of nature in mathematical terms, as mass, extension and motion, covered by the few universal laws of Newtonian mechanics. The mechanisation of nature created mind-body dualism, because the thing that never did seem to be physical was immediate experience: sense-perceptions, thinking, pain and the like. Physical objects including the human body have the primary qualities, while the mind was something else, immaterial and unlocated. Physicalism and dualism are twins, one born straight after the other, combative from the start, each refuting the other, the one supported by the great edifice of modern mechanics, the other known immediately by experience, battling ever since.

It is impossible to overstate the massive influence of modern physics and its accompanying philosophy of nature on the subsequent development of western science through the eighteenth and nineteenth centuries. As sciences developed, studying apparently distinctive domains and processes, the dominant physicalism applied its stringent reductionist test: either the new aspiring science was valid as causal science, in which case it should be reducible to physics, or, it was not reducible to physics, in which case it was pseudo-science, or at best, a 'science' studying noncauses. The chemistry that emerged in the nineteenth century passed the test and joined physics. As to biology, psychology and social science, on the other hand, physicalist reductionism aided by dualism caused disunity and more or less havoc - some key points in brief as follows, to be picked up in later chapters:

Biology as we now understand it developed in the nineteenth century, drawing from previous roots in medicine, natural history and botany (see e.g. Ernst Mayr's seminal work on the history and philosophy of biology, [93]). This large, complex field, comprising many subfields, with 
distinctive domains, questions and methods, had an ambiguous relation with physicalism and reductionism. In some areas of biology, especially in medicine, physiology and new subspecialities such as microbiologythere was the possibility of reduction of biological phenomena as chemistry. A key development was Lavoisier's work on the relation between combustion and respiration, initiating the scientific research programme that became biochemistry. However, for other parts of the broad and diverse field of biology, reducing the phenomena of life to chemistry was not such a clear option. This applied especially to developmental embryology and evolutionary biology, which aimed to understand the formation of individual organisms and whole species, and which used explanatory concepts more akin to older, Aristotelian concepts such as form and function. Such alternative concepts, contrasted with physics and chemistry, will appear in later chapters as we develop biopsychosocial theory. Biology could embrace physicalist reductionism, or ignore it, or argue against it head on. This third option was the doctrine of 'vitalism', which posited a biological life force in addition to mechanical, or more broadly physico-chemical, forces. Vitalism is in this sense a direct response to the mechanisation of the world picture in modern science, a point made by Bechtel and Richardson [94] (p. 1051):

Vitalism is best understood... in the context of the emergence of modern science during the sixteenth and seventeenth centuries. Mechanistic explanations of natural phenomena were extended to biological systems by Descartes and his successors. Descartes maintained that animals, and the human body, are 'automata', mechanical devices differing from artificial devices only in their degree of complexity. Vitalism developed as a contrast to this mechanistic view.

As to psychology, this new science inherited the Cartesian dualist assumptions: immaterial mind evident immediately in consciousness, and the mechanical body. Psychology struggled with the oddness of mind as its subject matter for several decades, then shifted to the other option, compatible with physicalism and reductionism, aligning psychology with physics and chemistry. This was behaviourism, and here is Watson [95] (p. 158) summarising the new approach:

Psychology, as the behaviorist views it, is a purely objective, experimental branch of natural science which needs introspection as little as do the 
sciences of chemistry and physics. It is granted that the behaviour of animals can be investigated without appeal to consciousness... This suggested elimination of states of consciousness as proper objects of investigation in themselves will remove the barrier from psychology which exists between it and the other sciences. The findings of psychology become the functional correlates of structure and lend themselves to explanation in physico-chemical terms.

The social sciences, on the other hand, as they emerged through the nineteenth century never were going to lend themselves to comprehension in physico-chemical terms. This would be desperate business. Their subject-matter was, briefly stated, forms and processes of social organisation, which looked a very long way from physics and chemistry, further away than even psychology. As to principles of social causation, perhaps there were universal laws governing change, but equally, social systems and events appeared as specific, even unique. In short, the ontology of the natural sciences was no use to the emerging social sciences, and their methodology was of limited or questionable use. Accordingly alternative approaches developed, drawing from philosophical traditions other than physicalism, emphasising understanding and meaning, 'hermeneutics', rather than causal explanation of nature. Here is Anthony Giddens on this point [96] (pp. viii-ix):

The tradition of the Geisteswissenschaften, or the 'hermeneutic' tradition, stretches back well before Dilthey, and from the middle of the eighteenth century onwards was intertwined with, but also partly set off from, the broader stream of Idealistic philosophy. Those associated with the hermeneutic viewpoint insisted upon the differentiation of the sciences of nature from the study of man. While we can 'explain' natural occurrences in terms of the application of causal laws, human conduct is intrinsically meaningful, and has to be 'interpreted' or 'understood' in a way which has no counterpart in nature. Such an emphasis linked closely with a stress upon the centrality of history in the study of human conduct, in economic action as in other areas, because the cultural values that lend meanings to human life, it was held, are created by specific processes of social development.

To sum up, physicalist reductionism had a massive influence on the development of the biological, psychological and social sciences. It prioritised physics, subsequently physics and chemistry, as the benchmark of empirical science and causal explanation. Parts of biology measured 
up, as biochemistry, evolutionary biology didn't; psychology struggled; and the social sciences were so far off the mark that new views of science including alternatives to causal explanation were needed.

Against this background, deeply entrenched theory, antithetical to any distinctive forms of biological (as opposed to physico-chemical), psychological and social causation, Engel's proposal of the biopsychosocial model was audacious. It was, however, prescient, because in the intervening decades the empirical evidence has built up, as outlined in Sect. 1.2, under the heading "Emerging Evidence of Psychosocial Causation". A main virtue of the empirical, empiricist methodology of Hume and Mill, outlined in Sect. 1.3, under the heading "Biopsychosocial Data in Search of Theory", is that it can accumulate evidence of causal connections, driving the science forwards, unhindered by theoretical prejudice. The scientific methodology for determining associations and causal connections between one or more factors and a health outcome in indifferent to the nature of the factor variables involved, in particular it has no interest in whether they are called 'biological', 'psychological' or 'social'; the methodology has no interest in ontological matters at all-it cares only that the variables are measurable. Equally the empirical and statistical methodology has not much or nothing to say about causal mechanisms. Free of the historical theoretical baggage, it has been able to study relations between biological, psychological and social factors and health outcomes of interest, the upshot of which has been accumulation of evidence that psychological and social factors are at least associated with some health outcomes, physical and mental, and with some evidence of causal impact. Such free creativity is typical of empirical science. On the other hand, the downside is that we have apparently established biopsychosocial ontology and causal interactions, but so far untheorised, andstill feeling the effects of physicalist reductionism in the last few centuries of science-with perplexity and incredulity that such a thing is possible.

\section{Theorising Biopsychosocial Interactions-Not Parallel Worlds}

The proposal of biopsychosocial ontology and causal relations-under the weight of philosophical and scientific prejudice according to which psychological and social causation are impossible, even incomprehensible, and there is no distinctive biological causation either, over and above physics and chemistry-is audacious and the task of making theoretical sense of it is non-trivial. 
Engel's biopsychosocial model is a very suitable heading for examining these issues. His papers certainly identified many of them, probably all that were apparent at the time he wrote them. However, Engel's model is only a heading for the major task of elucidating theory that can comprehend the paradigms and findings of the health sciences of the past few decades that invoke the full range of and interactions between biological, psychological and social factors in health and disease.

We propose to start with biology and especially its relation to physics and chemistry. It is the assumption that biology is no more than physics and chemistry that locks in the physicalist philosophy that the laws of physics and chemistry are the only causal laws. While that philosophical position remains in play, without viable alternative, it is difficult to make out any distinctive psychological or social causation and especially difficult to theorise biopsychosocial interactions. There is simply too much historical conceptual baggage in the way, variations of dualism and the disunity of the sciences.

We will be considering theory changes that have accelerated in the decades since Engel wrote. Up to the 1970s, just about everybody supposed that biology (as least as physiology) was reducible to physics and chemistry, but psychology and social sciences hardly, and so much the worse for them. In the 1970s, however, the reducibility of biology to physics became questionable, with recognition that all the 'special sciences', apart from physics/chemistry, had distinctive concepts and apparently causal explanations. However, exactly what the other sciences are sciences of, and what becomes of physicalism, dualism and reductionism, and especially how the various sciences are meant to relate to one another - all remained unclear and contested. Jerry Fodor's 1974 paper [97] had the full title 'Special Sciences (Or: The Disunity of Science as a Working Hypothesis)'. Fodor's 1997 [98] update was equally informatively titled, as 'Special Sciences: Still Autonomous After All These Years', concluding 'The world, it seems, runs in parallel, at many levels of description. You may find that perplexing...'

This parallel world view-or perhaps it should be parallel worlds plural-in which it is supposed that as well as the physico-chemical world, there is also a biological world (unless that is the same as the physico-chemical world), and a psychological world, and the social worldis certainly perplexing. It does not get much less perplexing if 'parallel world(s)' is replaced by 'many (parallel) levels of description'. Such a view however is exactly what is intellectually arrived at when forced to 
acknowledge, when no longer able to deny, that the biological, psychological and social sciences are now established as valid sciences including causal determinations, in some reasonable sense of 'causal', such as: can predict; when no longer able to deny this, while at the same time continuing to assume that the physico-chemical world is closed to anything other than physico-chemical causation.

This parallel worlds/levels of description approach can be applied in the health sciences, leading to the idea that psychological and social models of health and disease, as well as the biomedical, can somehow all be valid, but at different levels of description. As indicated previously in Sect. 1.1, Nassir Ghaemi argued that the biopsychosocial model has been used exactly to resolve turf wars between these various disciplines, by allowing them all to claim validity at the same time, the upshot being irredeemable vagueness and incoherence. We noted however that this thought is not prominent in Engel's papers, which philosophically relies rather on systems theory in which there is interaction between domains.

Philosophically, the parallel world(s) move, historically inevitable as it probably was, is not really coherent; what is needed rather is a more liberal view of worldly ontology and causation that can encompass not only physics and chemistry but also biological, psychological and social processes and principles of change. In any case, so far as the current sciences are concerned, and especially the health sciences, the idea of parallel causal explanations is unhelpful; rather, what is needed is theory of multifactorial interactive causation. Specifically, data of the sort reviewed in Sect. 1.2 under the heading "Emerging Evidence of Psychosocial Causation", suggesting biopsychosocial involvement in health and disease, need to be theorised in terms of biopsychosocial interactions. The quotes from Chris McManus, Ken Kendler and Dan Blazer considered at the beginning of this section, when setting up the task of the general biopsychosocial model, all refer to the need to integrate biological, psychological and social factors. Another aspect of the same point is that the various kinds of factors are found in the science to account for different proportions of the variance in health outcomes, with relative proportions of the three varying between health conditions and stages of condition. From the point of view of the science, a sentence along such lines as: 'biological, psychological and social factors (always) each severally account for $100 \%$ of the variance - at different levels of description'-is completely incomprehensible. 


\section{Finding the Right Metaphor: Evolution and Development}

It is not straightforward to find the right metaphor for the relation between the biological, the psychological and the social. The most common is in terms of hierarchical levels, but it suffers from reductionist connotations that lower levels are more basic, more causal, than higher ones. Alternatively, as a transitionary move away from reductionism, appraised in the previous section, it can be interpreted as different levels of ontology and/or description running in parallel, but this makes interactions mysterious. Systemic approaches that envisage interactions are the key, major improvement, but still the metaphors struggle. One, used by Engel in his 1980 paper [4], is 'nested squares' of systemic inter-activity, from the within-body biological, outwards to self-organised activity in the external environment, including interactions with immediate conspecifics, through to complex patterns of social organisation and regulation. This 'nested' domains metaphor is not up to much either, however, insofar as it lends itself to the implicit though odd presumption that the inner domain is sorted out first, then the next grows around it, then the next around that; in effect to the idea, absurd once spelt out, that our internal biology comes first, then activity in the outside world, then activity with conspecifics. This sequencing beginning with 'first' makes no sense temporally or systemically. Internal biology, functioning in the environment, including with other biological beings, cannot be separated from one another, conceptually or temporally.

What is missing from and obscured by these two-dimensional picture metaphors of levels and nested domains is the temporal, evolutionary and developmental, parameter. Everything is present in the original, primitive, prototypic forms. A cell is an individual unit, separate from but essentially interacting with the environment, extracting and expending energy, including interaction with other biological entities such as viruses. Parent sea birds catch fish and put it in the mouths of developmentally immature offspring, promoting the biologically necessary energetic reactions by bringing the chemicals into close enough proximity, acting like a catalyst-unless the fish is taken away first by a bigger bird of the same or different species. All these biological-environmental-individual-within-and-between-species-interactive processes are involved from the start in the simple forms, which become ever more complex. In short, no static metaphor, whether in terms of levels or nested systems, capable of being drawn on a page, does justice to the new systems sciences, which 
essentially invoke dynamical interaction in present time, on the basis of co-evolution through deep time.

\section{Developing the General Model}

Evolution and development involve increasing complexity of forms, and our argument will be that these forms bring with them new causal properties. Another way of expressing this is to say that what comes into being are increasingly complex systems, and that these systems have new and distinctive causal properties. There is in particular a quantum leap at the boundary between inanimate and biological material in which new forms or systems appear that manage the physics and chemistry of the matter, specifically energy exchanges governed by physico-chemical equations. This is the argument of Chapter 2, Sect. 2.1. The biological/ biomedical sciences in the last half-century have done all the work to undo the restrictive assumption that biology is only physics and chemistry and to construct instead new deep theory involving another kind of ontology, turning on dynamical forms, and causation as regulation and control. The way out of physicalist reductionism starts here-exactly at the place where physics and chemistry become biology. This is the argument of Chapter 2, Sect. 2.2.

The evolution of life forms ends up with human psychological and social phenomena. This 'ends up with', as currently understood in the science, is not a matter of logic or scientific law, but is entirely contingent-accidental. In this sense, biopsychosocial systems theory is unlike some traditional philosophical systems, which start with axioms and deduce the rest, or which elucidate natural law that covers everything. So when we move from defining key features of biology, in Chapter 2, to defining key features of psychological and hence social phenomena in Chapter 3, there is a gap, evident at the start in Sect. 3.1, one which cannot be filled in by logic or natural law, but only by contingent facts of evolution, development and change.

Human psychological and social phenomena have lives of their ownmultiple distinctive modes of operation, turning on systemic concepts and principles already evident in biology, such as form, organisation, ends, communication, rules and regulations. In the evolution and development of new forms or systems, it can be said that they all share-from the start, and remaining in-the same 'ontological space/time'. This is a good way of capturing the fact that they can bump into one another and affect one 
another, that they causally interact, as opposed to being in parallel universes. This is to say, the ontological point is at the same time essentially a point about causal interaction. We propose defining key features of psychosocial phenomena and causation in the first sections of Chapter 3, Sects. 3.1-3.4, consistent with the key features of biology proposed in Chapter 2. With the whole biopsychosocial system in view, we return in Sect. 3.4, to the general theory of biopsychological systems, interwoven ontology and causal theory. We address the vexed issues of top-down causes, vexed from the point of view of physicalist reductionism: psychological effects on biological processes, and social effects on our biology and psychology. However, by this stage in the argument-and in the current science we intend to be tracking-the prejudicial concepts and assumptions of physicalist reductionism are nowhere to be seen. Rather, in the new approach, there are coherent core concepts and principles of causation by regulatory control, which are found already in biology, and which can elucidate in a relatively straightforward way the logic of what is traditionally regarded as top-down processing in biological, psychological and social domains. In brief, control mechanisms employ agents at the lower level, compliant with any laws that may apply at that level, but also acting as messengers from higher levels, defined by networks of relations at those higher levels.

The detailed arguments elucidating the general theory of biopsychosocial interactions are developed through the next two chapters. The fourth chapter expands on relevance to health and disease. In fact, however, the whole theory is at its core, from the start, a theory of health and disease. This is because the theory is fundamentally normative, in terms of concepts such as functioning well or badly, being well or unwell. The contrast here with physicalist reductionism is striking: the old theory makes a point of excluding any hint of normativity, with no interest in any difference between life and death or anything else related.

\section{REFERENCES}

1. Engel, G. L. (1977). The need for a new medical model: A challenge for biomedicine. Science, 196(4286), 129-136.

2. Ghaemi, S. N. (2010). The rise and fall of the biopsychosocial model: Reconciling art and science in psychiatry. Baltimore, MD: Johns Hopkins University Press.

3. Kendler, K. S. (2010). [Book Review] The rise and fall of the biopsychosocial model: Reconciling art and science in psychiatry. American 
Journal of Psychiatry, 167(8), 999-1000. https://doi.org/10.1176/appi. ajp.2010.10020268.

4. Engel, G. L. (1980). The clinical application of the biopsychosocial model. American Journal of Psychiatry, 137(5), 535-544.

5. Marmot, M. (2010). Fair society, healthy lives: Strategic review of health inequalities in England post-2010. London, UK: Department of Health.

6. Frankel, R. M., Quill, T. E., \& McDaniel, S. H. (Eds.). (2003). The biopsychosocial approach: Past, present, and future. Rochester, NY: University of Rochester Press.

7. Sadler, J. Z., \& Hulgus, Y. F. (1990). Knowing, valuing, acting: Clues to revising the biopsychosocial model. Comprehensive Psychiatry, 31(3), 185-195.

8. Lindau, S. T., Laumann, E. O., Levinson, W., \& Waite, L. J. (2003). Synthesis of scientific disciplines in pursuit of health: The interactive biopsychosocial model. Perspectives in Biology and Medicine, 46(Suppl. 3), S74-S86.

9. Smith, R. C., Fortin, A. H., Dwamena, F., \& Frankel, R. M. (2013). An evidence-based patient-centered method makes the biopsychosocial model scientific. Patient Education and Counseling, 91(3), 265-270. https://doi. org/10.1016/j.pec.2012.12.010.

10. Ghaemi, S. N. (2009). The rise and fall of the biopsychosocial model. The British Journal of Psychiatry, 195(1), 3-4.

11. Engel, G. L. (1978). The biopsychosocial model and the education of health professionals. General Hospital Psychiatry, 1(2), 156-165.

12. Davey Smith, G. (2005). The biopsychosocial approach: A note of caution. In P. D. White (Ed.), Biopsychosocial medicine: An integrated approach to understanding illness (pp. 77-102). New York, NY: Oxford University Press.

13. McManus, C. (2005). Engel, Engels, and the side of the angels. The Lancet, 365(9478), 2169-2170. https://doi.org/10.1016/S0140-6736 (05)66761-X.

14. Marmot, M. (2005). Remediable or preventable social factors in the aetiology and prognosis of medical disorders. In P. D. White (Ed.), Biopsychosocial medicine: An integrated approach to understanding illness (pp. 39-58). New York, NY: Oxford University Press.

15. Marmot, M. (2006). Status syndrome: A challenge to medicine. Journal of the American Medical Association, 295(11), 1304-1307.

16. Marmot, M. G., Rose, G., Shipley, M., \& Hamilton, P. J. (1978). Employment grade and coronary heart disease in British civil servants. Journal of Epidemiology and Community Health, 32(4), 244-249.

17. Link, B. G., \& Phelan, J. (1995). Social conditions as fundamental causes of disease. Journal of Health and Social behavior, Special Issue, 80-94.

18. Cockerham, W. C. (2007). Social causes of health and disease. Cambridge: Polity Press. 
19. Felitti, V. J., Anda, R. F., Nordenberg, D., Williamson, D. F., Spitz, A. M., Edwards, V., et al. (1998). Relationship of childhood abuse and household dysfunction to many of the leading causes of death in adults. The Adverse Childhood Experiences (ACE) Study. American Journal of Preventative Medicine, 14(4), 245-258.

20. Adler, N. E., Epel, E. S., Castellazzo, G., \& Ickovics, J. R. (2000). Relationship of subjective and objective social status with psychological and physiological functioning: Preliminary data in healthy, white women. Health Psychology, 19(6), 586-592.

21. Singh-Manoux, A., Adler, N. E., \& Marmot, M. G. (2003). Subjective social status: Its determinants and its association with measures of ill-health in the WhiteHall II study. Social Science and Medicine, 56(6), 1321-1333.

22. Beck, A. T., Rush, A. J., Shaw, B. F., \& Emery, G. (1979). Cognitive therapy of depression. New York, NY: Guilford Press.

23. Hunsley, J., Elliott, K., \& Therrien, Z. (2013). The efficacy and effectiveness of psychological treatments. Report to the Canadian Psychologial Association. https://cpa.ca/docs/File/Practice/TheEfficacyAndEffectivenessOf PsychologicalTreatments_web.pdf. Accessed 21 December 2018.

24. Falagas, M. E., Zarkadoulia, E. A., Ioannidou, E. N., Peppas, G., Christodoulou, C., \& Rafailidis, P. I. (2007). The effect of psychosocial factors on breast cancer outcome: A systematic review. Breast Cancer Research, 9(4), R44. https://doi.org/10.1186/bcrl744.

25. Chida, Y., Hamer, M., \& Steptoe, A. (2008). A bidirectional relationship between psychosocial factors and atopic disorders: A systematic review and meta-analysis. Psychosomatic Medicine, 70(1), 102-116.

26. Ritz, T., Meuret, A. E., Trueba, A. F., Fritzsche, A., \& von Leupoldt, A. (2013). Psychosocial factors and behavioral medicine interventions in asthma. Journal of Consulting and Clinical Psychology, 81(2), 231-250.

27. Chida, Y., \& Vedhara, K. (2009). Adverse psychosocial factors predict poorer prognosis in HIV disease: A meta-analytic review of prospective investigations. Brain, Behavior, and Immunity, 23(4), 434-445.

28. Ironson, G. H., \& Hayward, H. (2008). Do positive psychosocial factors predict disease progression in HIV-1? A review of the evidence. Psychosomatic Medicine, 70(5), 546-554.

29. Langford, S. E., Ananworanich, J., \& Cooper, D. A. (2007). Predictors of disease progression in HIV infection: A review. AIDS Research and Therapy, $4(1), 1-11$.

30. Laisné, F., Lecomte, C., \& Corbière, M. (2012). Biopsychosocial predictors of prognosis in musculoskeletal disorders: A systematic review of the literature (corrected and republished). Disability and Rehabilitation, 34(22), 1912-1941. 
31. Berk, H. O. S. (2010). The biopsychosocial factors that serve as predictors of the outcome of surgical modalities for chronic pain. Agri, 22(3), 93-97.

32. Block, A. R., Ben-Porath, Y. S., \& Marek, R. J. (2013). Psychological risk factors for poor outcome of spine surgery and spinal cord stimulator implant: A review of the literature and their assessment with the MMPI2-RF. The Clinical Neuropsychologist, 27(1), 81-107.

33. Celestin, J., Edwards, R. R., \& Jamison, R. N. (2009). Pretreatment psychosocial variables as predictors of outcomes following lumbar surgery and spinal cord stimulation: A systematic review and literature synthesis. Pain Medicine, 10(4), 639-653.

34. den Boer, J. J., Oostendorp, R. A. B., Beems, T., Munneke, M., Oerlemans, M., \& Evers, A. W. M. (2006). A systematic review of bio-psychosocial risk factors for an unfavourable outcome after lumbar disc surgery. European Spine Journal, 15(5), 527-536.

35. Epker, J., \& Block, A. R. (2001). Presurgical psychological screening in back pain patients: A review. The Clinical Journal of Pain, 17(3), 200-205.

36. Gaudin, D., Krafcik, B. M., Mansour, T. R., \& Alnemari, A. (2017). Considerations in spinal fusion surgery for chronic lumbar pain: Psychosocial factors, rating scales, and perioperative patient education. World Neurosurgery, 98, 21-27.

37. Lall, M. P., \& Restrepo, E. (2017). The biopsychosocial model of low back pain and patient-centered outcomes following lumbarfusion. Orthopaedic Nursing, 36(3), 213-221.

38. Wilhelm, M., Reiman, M., Goode, A., Richardson, W., Brown, C., Vaughn, D., et al. (2015). Psychological predictors of outcomes with lumbar spinal fusion: A systematic literature review. Physiotherapy Research International, 22(2), el648.

39. Fineberg, S. K., West, A., Na, P. J., Oldham, M., Schilsky, M., Hawkins, K. A., et al. (2016). Utility of pretransplant psychological measures to predict posttransplant outcomes in liver transplant patients: A systematic review. General Hospital Psychiatry, 40, 4-11.

40. Pignay-Demaria, V., Lespérance, F., Demaria, R. G., Frasure-Smith, N., \& Perrault, L. P. (2003). Depression and anxiety and outcomes of coronary artery bypass surgery. The Annals of Thoracic Surgery, 75(1), 314-321.

41. Rosenberger, P. H., Jokl, P., \& Ickovics, J. (2006). Psychosocial factors and surgical outcomes: An evidence-based literature review. Journal of the American Academy of Orthopaedic Surgeons, 14(7), 397-405.

42. Tully, P. J., \& Baker, R. A. (2012). Depression, anxiety, and cardiac morbidity outcomes after coronary artery bypass surgery: A contemporary and practical review. Journal of Geriatric Cardiology, 9(2), 197-208.

43. Alexander, S. J. (2013). Time to get serious about assessing-and managing-psychosocial issues associated with chronic wounds. Current Opinion in Supportive and Palliative Care, 7(1), 95-100. 
44. Soon, K., \& Acton, C. (2006). Pain-induced stress: A barrier to wound healing. Wounds UK, 2(4), 92-101.

45. Mollayeva, T., Kendzerska, T., Mollayeva, S., Shapiro, C. M., Colantonio, A., \& Cassidy, J. D. (2014). A systematic review of fatigue in patients with traumatic brain injury: The course, predictors and consequences. Neuroscience and Biobehavioral Reviews, 47, 684-716.

46. Chang, E. Y., Chang, E., Cragg, S., \& Cramer, S. C. (2013). Predictors of gains during inpatient rehabilitation in patients with stroke: A review. Critical Reviews in Physical and Rebabilitation Medicine, 25(3-4), 203-221.

47. Admi, H., Shadmi, E., Baruch, H., \& Zisberg, A. (2015). From research to reality: Minimizing the effects of hospitalization on older adults. Rambam Maimonides Medical Journal, 6(2), e0017. https://doi.org/10.5041/ RMMJ.10201.

48. Felix-Aaron, K., Moy, E., Kang, M., Patel, M., Chesley, F. D., \& Clancy, C. (2005). Variation in quality of men's health care by race/ethnicity and social class. Medical Care, 43(3), I-72-I-81.

49. Grintsova, O., Maier, W., \& Mielck, A. (2014). Inequalities in health care among patients with type 2 diabetes by individual socio-economic status (SES) and regional deprivation: A systematic literature review. International Journal for Equity in Health, 13(1), 43. http://www.equityhealthj.com/ content $/ 13 / 1 / 43$.

50. Davidson, E., Liu, J. J., \& Sheikh, A. (2010). The impact of ethnicity on asthma care. Primary Care Respiratory Journal, 19(3), 202-208.

51. Crawshaw, J., Auyeung, V., Norton, S., \& Weinman, J. (2016). Identifying psychosocial predictors of medication non-adherence following acute coronary syndrome: A systematic review and meta-analysis. Journal of Psychosomatic Research, 90, 10-32.

52. Ghimire, S., Castelino, R. L., Lioufas, N. M., Peterson, G. M., \& Zaidi, S. T. R. (2015). Nonadherence to medication therapy in haemodialysis patients: A systematic review. PLoS One, 10(12), e0144119.

53. Loiselle, K., Rausch, J. R., \& Modi, A. C. (2015). Behavioral predictors of medication adherence trajectories among youth with newly diagnosed epilepsy. Epilepsy \& Behavior, 50, 103-107.

54. Zwikker, H. E., van den Bemt, B. J. F., Vriezekolk, J. E., van den Ende, C. H. M., \& Dulmen, S. (2014). Psychosocial predictors of non-adherence to chronic medication: Systematic review of longitudinal studies. Patient Preference and Adherence, 8, 519-563.

55. Edwards, R. R., Dworkin, R. H., Sullivan, M. D., Turk, D. C., \& Wasan, A. D. (2016). The role of psychosocial processes in the development and maintenance of chronic pain. The Journal of Pain, 17(9), T70-T92.

56. Ong, K. S., \& Keng, S. B. (2003). The biological, social, and psychological relationship between depression and chronic pain. The Journal of Craniomandibular \& Sleep Practice, 21(4), 286-294. 
57. Harrison, A. M., McCracken, L. M., Bogosian, A., \& Moss-Morris, R. (2015). Towards a better understanding of MS pain: A systematic review of potentially modifiable psychosocial factors. Journal of Psychosomatic Research, $78(1), 12-24$.

58. Mallen, C. D., Peat, G., Thomas, E., Dunn, K. M., \& Croft, P. R. (2007). Prognostic factors for musculoskeletal pain in primary care: A systematic review. British Journal of General Practice, 57(541), 655-661.

59. Whibley, D., Martin, K. R., Lovell, K., \& Jones, G. T. (2015). A systematic review of prognostic factors for distal upper limb pain. British Journal of Pain, 9(4), 241-255.

60. Pincus, T., Burton, A. K., Vogel, S., \& Field, A. P. (2002). A systematic review of psychological factors as predictors of chronicity/disability in prospective cohorts of low back pain. Spine, 27(5), E109-E120.

61. Ramond-Roquin, A., Bouton, C., Bègue, C., Petit, A., Roquelaure, Y., \& Huez, J. F. (2015). Psychosocial risk factors, interventions, and comorbidity in patients with non-specific low back pain in primary care: Need for comprehensive and patient-centered care. Frontiers in Medicine, 2(73), 1-6.

62. Campbell, P., Wynne-Jones, G., \& Dunn, K. M. (2011). The influence of informal social support on risk and prognosis in spinal pain: A systematic review. European Journal of Pain, 15(5), 444. el-14. https://doi. org/10.1016/j.ejpain.2010.09.011.

63. Riegel, B., Bruenahl, C. A., Ahyai, S., Bingel, U., Fisch, M., \& Löwe, B. (2014). Assessing psychological factors, social aspects and psychiatric co-morbidity associated with Chronic Prostatitis/Chronic Pelvic Pain Syndrome (CP/CPPS) in men: A systematic review. Journal of Psychosomatic Research, 77(5), 333-350.

64. Somers, T. J., Keefe, F. J., Godiwala, N., \& Hoyler, G. H. (2009). Psychosocial factors and the pain experience of osteoarthritis patients: New findings and new directions. Current Opinion in Rbeumatology, 21(5), 501-506.

65. Novy, D. M., \& Aigner, C. J. (2014). The biopsychosocial model in cancer pain. Current Opinion in Supportive and Palliative Care, 8(2), 117-123.

66. Schreiber, K. L., Kehlet, H., Belfer, I., \& Edwards, R. R. (2014). Predicting, preventing and managing persistent pain after breast cancer surgery: The importance of psychosocial factors. Pain, 4(6), 445-459.

67. Von Korff, M. (2005). Fear and depression as remediable causes of disability in common medical conditions in primary care. In P. D. White (Ed.), Biopsychosocial medicine: An integrated approach to understanding illness (pp. 117-131). New York, NY: Oxford University Press.

68. Naylor, C., Parsonage, M., McDaid, D., Knapp, M., Fossey, M., \& Galea, A. (2012). Long-term conditions and and mental health: The cost of co-morbidities. The King's Fund and Centre for Mental Health. Available at 
https://www.kingsfund.org.uk/sites/default/files/field/field_publication_ file/long-term-conditions-mental-health-cost-comorbidities-naylor-febl2. pdf. Accessed 21 December 2018.

69. Parle, M., Jones, B., \& Maguire, P. (1996). Maladaptive coping and affective disorders among cancer patients. Psychological Medicine, 26(4), 735-744.

70. Cordella, M., \& Poiani, A. (2004). Behavioural Oncology: Psychological, communicative, and social dimensions. New York, NY: Springer-Verlag.

71. NHS England \& NHS Improvement. (2018). The Improving Access to Psychological Therapies (IAPT) pathway for people with long-term physical bealth conditions and medically unexplained symptoms. London, UK: NHS.

72. Allart, P., Soubeyran, P., \& Cousson-Gélie, F. (2013). Are psychosocial factors associated with quality of life in patients with haematological cancer? A critical review of the literature. Psycho-Oncology, 22(2), 241-249.

73. Bakaniene, I., Prasauskiene, A., \& Vaiciene-Magistris, N. (2016). Healthrelated quality of life in children with myelomeningocele: A systematic review of the literature. Child: Care, Health and Development, 42(5), 625-643.

74. Sales, P. M. G., Carvalho, A. F., McIntyre, R. S., Pavlidis, N., \& Hyphantis, T. N. (2014). Psychosocial predictors of health outcomes in colorectal cancer: A comprehensive review. Cancer Treatment Reviews, 40(6), 800-809.

75. Bours, M. J. L., van der Linden, B. W. A., Winkels, R. M., van Duijnhoven, F. J., Mols, F., van Roekel, E. H., et al. (2016). Candidate predictors of health-related quality of life of colorectal cancer survivors: A systematic review. Oncologist, 21(4), 433-452.

76. Kang, K., Gholizadeh, L., Inglis, S. C., \& Han, H. R. (2017). Correlates of health-related quality of life in patients with myocardial infarction: A literature review. International Journal of Nursing Studies, 73, 1-16.

77. Peeters, C. M. M., Visser, E., Van de Ree, C. L. P., Gosens, T., Den Oudsten, B. L., \& De Vries, J. (2016). Quality of life after hip fracture in the elderly: A systematic literature review. Injury, 47(7), 1369-1382.

78. Pragodpol, P., \& Ryan, C. (2013). Critical review of factors predicting health-related quality of life in newly diagnosed coronary artery disease patients. Journal of Cardiovascular Nursing, 28(3), 277-284.

79. Taylor, R. S., Sander, J. W., Taylor, R. J., \& Baker, G. A. (2011). Predictors of health-related quality of life and costs in adults with epilepsy: A systematic review. Epilepsia, 52(12), 2168-2180.

80. Seiam, A. H. R., Dhaliwal, H., \& Wiebe, S. (2011). Determinants of quality of life after epilepsy surgery: Systematic review and evidence summary. Epilepsy \& Behavior, 21(4), 441-445.

81. Walders-Abramson, N. (2014). Depression and quality of life in youth-onset type 2 diabetes mellitus. Current Diabetes Reports, 14(1), 449. https://doi. org/10.1007/s11892-013-0449-x. 
82. Blazer, D. (2010). [Book Review] The rise and fall of the biopsychosocial model: Reconciling art and science in psychiatry. The International Journal of Psychiatry in Medicine, 40(3), 361-362. https://doi.org/10.2190/ PM.40.3.j.

83. Mill, J. S. (1843). A system of logic. London: John W. Parker.

84. Hume, D. (1902). An enquiry concerning human understanding (L. A. Selby-Bigge, Ed.). Oxford: Oxford University Press (Original work published 1777).

85. Koch, R. (1890). Uber bacteriologische forschung. Deutsche Medizinische Wochenschrift, 16, 756-757.

86. Evans, A. (1976). Causation and disease: The Henle-Koch postulates revisited. The Yale Journal of Biology and Medicine, 49, 175-195.

87. Bolton, D. (2008). The epistemology of randomized, controlled trials and application in psychiatry. Philosophy, Psychiatry \& Psychology, 15(2), 159-165.

88. Rutter, M. (2000). Psychosocial influences: Critiques, findings, and research needs. Development and Psychopathology, 12(3), 375-405. https://doi. org/10.1017/S0954579400003072.

89. Stoljar, D. (2015)., "Physicalism", The Stanford Encyclopedia of Philosophy (Winter 2017 Edition), Edward N. Zalta (ed.), URL = <https://plato.stanford.edu/archives/win2017/entries/physicalism/>. Accessed 12/21/2018.

90. Burtt, E. A. (1932). The metaphysical foundations of modern physical sciences. London: Routledge and Kegan Paul.

91. Dijksterhuis, E. J. (1961). The mechanization of the world picture (C. Dikshoorn, Trans.). Oxford: Oxford University Press.

92. Koyré, A. (1968). Metaphysics and measurement: Essays in the scientific revolution. London: Chapman and Hall.

93. Mayr, E. (1982). The growth of biological thought: Diversity, evolution, and inheritance. Cambridge, MA: Harvard University Press.

94. Bechtel, W., \& Richardson, R. C. (2005). Vitalism. In E. Craig (Ed.), The shorter Routledge encyclopedia of philosophy (p. 1051). Oxford: Routledge.

95. Watson, J. B. (1913). Psychology as the behaviorist views it. Psychological Review, 20(2), 158-177.

96. Giddens, A. (2005). Introduction to the protestant ethic and the spirit of capitalism, by Max Weber (T. Parsons, Trans.). London: Routledge.

97. Fodor, J. (1974). Special sciences (Or: The disunity of science as a working hypothesis). Synthese, 28(2), 97-115.

98. Fodor, J. (1997). Special sciences: Still autonomous after all these years. Philosophical Perspectives, 11, 149-163. 
Open Access This chapter is licensed under the terms of the Creative Commons Attribution 4.0 International License (http://creativecommons.org/licenses/ by $/ 4.0 /$ ), which permits use, sharing, adaptation, distribution and reproduction in any medium or format, as long as you give appropriate credit to the original author(s) and the source, provide a link to the Creative Commons license and indicate if changes were made.

The images or other third party material in this chapter are included in the chapter's Creative Commons license, unless indicated otherwise in a credit line to the material. If material is not included in the chapter's Creative Commons license and your intended use is not permitted by statutory regulation or exceeds the permitted use, you will need to obtain permission directly from the copyright holder.

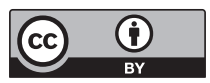

